\title{
BLOOD VISEOSITY IN PATIENTS WITH DIABETIC NEPHROPATHY VERSUS BLOOD VISEOSITY IN HEALTHY PATIENTS
}

\section{Tudorache Monica' , Hanzu-Pazara Loredana', Dușa Daniela1, Ion Ileana1}

${ }^{1}$ Faculty of Medicine, University “Ovidius” of Constanta

Loredana Hanzu-Pazara

Faculty of Medicine, Univeristy ,, Ovidius” of Constanta, Universitatii Alee No. 1, Campus B, Constanta, Romania email:loredanapazara@yahoo.com phone: +40723583952

\section{ABSTRACT}

Diabetic nephropathy is the major cause of severe renal impairment and even chronic terminal renal failure requiring dialysis. Blood viscosity is clearly modified in diabetic patients, and particularly in those with severe renal impairment

The purpose of this study is to highlight blood viscosity values at different shear rates in patients with diabetic nephropathy compared to the control group.

There is a significant increase in blood viscosity in patients with definite renal impairment.

Keywords:shear rate, renal impairment, increase blood viscosity

\section{Introduction}

Diabetic nephropathy is a progressive renal disease occurring in approximately $30 \%$ and even up to $50 \%$ of patients diagnosed with diabetes mellitus (DM) $(1,2)$. The histological feature is represented by diabetic glomerulosclerosis, that is clinically manifested through a progressivelly increasing proteinuria rate, leading to gradual reduction of renal function up to end stage renal disease (ESRD) $(3,4,5,6)$. Diabetic nephropathy is the leading cause of terminal chronic renal failure (ESRD) in developed countries.

An increasing concern related to the improvement of care for patients with kidney diseases has developed worldwide. According to the data recently published in the US, there are strong evidences of clear progression from diabetic kidney disease to ESRD, as the results state in the observations for Asian countries, or even Russia (e.g.: there is an increase in the incidence of the disease in Malaysia of $212.1 \%$ in $2014 / 2015$ compared with $2002 / 2003$, or in Philippines of $324.9 \%$; in Russia, the increase is of $702.9 \%$ in $2014 / 2015$ compared with 2002/2003). Conversely, western Europe faces a reduction in the rate of disease progression (countriwes like: Austria - 25.7\%, Finland -11.3\% decrease in the number of cases with evolution to $\operatorname{ESRD}(7)$ ) . 
In Romania, the exact trend cannot be estimated because the data collected are incomplete (evidences for 2002 and 2003 are absent), but it has been observed a definite increase, especially in recent years (7).

\begin{tabular}{l|ccccccccccc|} 
Year & 2005 & 2006 & 2007 & 2008 & 2009 & 2010 & 2011 & 2012 & 2013 & 2014 & 2015 \\
\hline Incidence \% & 10.1 & 9.2 & 10.5 & 12.1 & 15.7 & 19.6 & 18.4 & 19.7 & 21.9 & 22.2 & 17.9
\end{tabular}

Figure 1. Trends in the incidence rate (per million population/year) of treated ESRD due to diabetes, in Romania , 2002-2015(7)

There were made several classifications for diabetic nephropathy according to pathophysiological criteria, but also by some clinical criteria, such as: glomerular filtration, albuminuria, blood pressure values and the duration of progression of diabetic disease.

Table I. Classification of diabetic nephropathy (Gerhard and Schmeisl (8))

\begin{tabular}{|l|l|l|}
\hline Stage & $\begin{array}{l}\text { UAE } \\
\mathbf{m g} / \mathbf{l}\end{array}$ & $\begin{array}{l}\text { GFR } \\
\mathbf{~ m l} / \mathbf{m i n} / \mathbf{1 . 7 3} \mathbf{m}^{\mathbf{2}}\end{array}$ \\
\hline \multicolumn{3}{|l|}{ Renal impairment with normal renal function } \\
\hline A.Microalbuminuria & $20-200$ & $>90$ \\
\hline B.Macroalbuminuria & $>200$ & $>90$ \\
\hline 2.Renal impairment with decrease renal function \\
\hline A. mild nephropathy & $>200$ & $60-89$ \\
\hline B. overt nephropathy & $>200$ & $30-59$ \\
\hline C. kidney failure & $>200$ & $15-29$ \\
\hline D. ESRD & Decreasing & $<15$ \\
\hline
\end{tabular}

$U A E$ - urinary albumin excretion,

GFR - glomerular filtration rate

The International Committee for Diabetic Nephropathy has revised the Classification of Diabetic Nephropathy in 2014 according to the use of key concepts such as Chronic Kidney Disease and estimated Glomerular Filtration Rate (eGFR). In reviewing the classification, the International Committee considered relevant a study by the Ministry of Health, Labor and Welfare of Japan and the Diabetic Nephropathy Research Group.

Major revisions to the classification are summarized as follows:

(1) EGFR is replaced by GFR in classification;

(2) Subdivisions A and B of step 3 (manifest nephropathy) were reintegrated;
(3) Stage 4 (renal failure) was redefined as a GFR $<30 \mathrm{ml} / \mathrm{min} / 1.73 \mathrm{~m} 2$, regardless the degree of albuminuria;

(4) Stress has been included as criteria in all stages for the differential diagnosis of diabetic nephropathy to non-diabetic kidney disease (9).

Viscosity and elasticity are the necessary components that ensure pressure in the blood circulation. Due to the correlations found between total blood viscosity and some diseases such as stroke, hypertension or diabetes, hemorheology is of great interest in biomedical engineering and medical research.

\section{Material and method}

Analyzed sample of cases included 72 diabetic patients with varying degrees of renal impairment. In accordance with the degree of renal impairment, they were divided into three groups adjusted by age and sex. The first group included 16 patients without renal impairment (grades $1 \mathrm{~A}$ and $\mathrm{B}$ according to Table 1) with an average age of $61.75+/-11.15$ years and a male/ female ratio of $8 / 8$. The second group consisted of 28 patients with renal impairment classes $2 \mathrm{~A}$, $2 \mathrm{~B}$ according to Table 1, with an average age of $67.71+/-9.60$ years and a male/female ratio of 20/8. The third group included also 28 patients with severe renal impairment corresponding to Class $2 \mathrm{C}$ and $2 \mathrm{D}$ according to Table 1 with an average age of $64.14+/-12.88$ years and a male/female ratio of $16 / 12$. The control group, consisting of 36 healthy patients, presented an average age of $40.66+/-12.35$ years and a sex ratio of 32/4 (male/female).

For all patients and control group there were determined the blood viscosity values at different shear rates, using the Brookfield viscometer in accordance with the instructions of sampling validating the results.

\section{Results}

The biological parameters influencing the rheological character of the blood, namely the determination of hemoglobin and hematocrit, revealed that in terms of hemoglobin values there was no statistically significant difference between the group 1 and the control group ( $p=0.00241)$; 
Table II. Comparisson between haematological parameters in studied groups vs.controls

\begin{tabular}{|l|l|l|l|l|r|}
\hline $\begin{array}{c}\text { Haematological } \\
\text { parametres }\end{array}$ & \multicolumn{1}{|c|}{$\begin{array}{c}\text { Group 1 } \\
\text { No 16 }\end{array}$} & $\begin{array}{c}\text { Group 2 } \\
\text { No 28 }\end{array}$ & $\begin{array}{c}\text { Group 3 } \\
\text { No 28 }\end{array}$ & $\begin{array}{c}\text { Control } \\
\text { No 36 }\end{array}$ & P value \\
\hline Hb (average+/-sd) & $12,73+/-2,67$ & $11,42+/-2,64$ & $9,82+/-1,46$ & $14,79+/-0,74$ & 0,00241 \\
& & & & & $<0.00001$ \\
& & & & $45,06+/-1,70$ & $<0.00001$ \\
\hline Ht (average+/-sd) & $37,74+/-8,41$ & $35,27+/-7,03$ & $29,60+/-4,89$ & & $<, 0006$ \\
& & & & & $<0.00001$ \\
& & & & & $<0.00001$ \\
\hline
\end{tabular}

converselly, in case of patients of groups 2 and 3 there was observed a statistically significant difference $-\mathrm{p}<0.00001$ (Table II).

Regarding the renal impairment parameters, it can be observed that for the glomerular filtration rate and creatinine values there are statistically significant differences between the control group and all three groups of patients with renal impairment. Blood urea nitrogen (BUN) presented no statistical difference in the group 1 compared with controls; only in the case of patients with existing renal impairment, respectively group $2(\mathrm{p}=0.0001)$ and group 3 $(p<0.00001)$ there were significantly increased measurements (Table III).

The selection of viscosity at high shear rates was made for important reasons, namely that there are strong correlations at this high rates, but also because the increased shear values correspond to hemodynamics in the arterioles and capillary vessels where the viscosity appears to influence the sea measure blood flow.

Table IV is showing the average values of viscosity measured in the groups, adjusted to the controls.

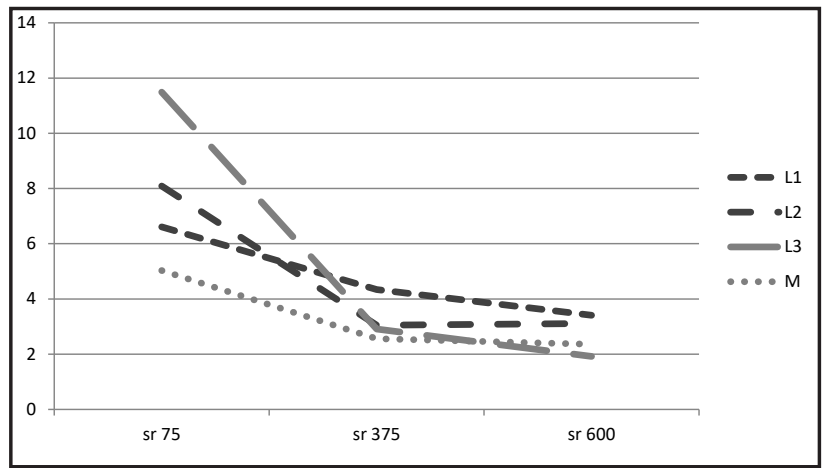

Figure 2. Comparison of viscosity values in patients with different degrees of renal impairment and control group

At low shear rates, a considerable increase in blood viscosity values is observed in diabetic patients compared to the control group, even a $16 \%$ increase in patients with severe renal impairment (Figure 2).

Table III. Comparisson between haematological parameters in studied groups vs.controls

\begin{tabular}{|c|c|c|c|c|c|}
\hline Renal parameters & $\begin{array}{c}\text { Group } 1 \\
\text { No } 16\end{array}$ & $\begin{array}{c}\text { Group } 2 \\
\text { No } 28\end{array}$ & $\begin{array}{c}\text { Group } 3 \\
\text { No } 28\end{array}$ & $\begin{array}{c}\text { Control } \\
\text { No } 36\end{array}$ & P value \\
\hline $\begin{array}{l}\text { GFR } \\
\text { (average+/-sd) }\end{array}$ & $74,37+/-15,13$ & $43,98+/-9,06$ & $15,67+/-7,55$ & $104,55+/-15,87$ & $\begin{array}{l}<0.00001 \\
<0.00001 \\
<0.00001\end{array}$ \\
\hline $\begin{array}{l}\text { Creatinine } \\
\text { (average+/-sd) }\end{array}$ & $0,94+/-0,16$ & $1,63+/-0,45$ & $5,22+/-2,63$ & $0,85+/-0,10$ & $\begin{array}{l}<0.00001 \\
<0.00001 \\
<0.00001\end{array}$ \\
\hline $\begin{array}{l}\text { BUN } \\
\text { (average+/-sd) }\end{array}$ & $32,37+/-11,91$ & $\begin{array}{l}60,31+/- \\
38,46\end{array}$ & $\begin{array}{l}132,24+/- \\
51,25\end{array}$ & $33,38+/-5,41$ & $\begin{array}{c}0,5776 \\
0,0001 \\
<0.00001\end{array}$ \\
\hline
\end{tabular}

Table IV. Values of viscosity in diabetic nephropathy groups and controls

\begin{tabular}{|l|l|l|l|}
\hline $\begin{array}{l}\text { Values } \\
(\text { mean+/-sd) }\end{array}$ & $\begin{array}{l}\text { Viscosity of blood at } \\
\mathbf{1 0} \text { rot } / \mathbf{m i n} \\
\text { Shear rate 75 } \mathbf{~ s e c}\end{array}$ & $\begin{array}{l}\text { Viscosity of blood at } \\
\mathbf{5 0} \text { rot } / \mathbf{m i n} \\
\text { Shear rate } \mathbf{3 7 5} \mathbf{s e c}^{-1}\end{array}$ & $\begin{array}{l}\text { Viscosity of blood at } \\
\mathbf{8 0} \mathbf{~ r o t} / \mathbf{m i n} \\
\text { Shear } \mathbf{~ r a t e ~} \mathbf{6 0 0} \mathbf{s e c}^{-1}\end{array}$ \\
\hline Group 1 & $6,61+/-3,71$ & $4,34+/-1,01$ & $3,41+/-0,12$ \\
\hline Group 2 & $6,98+/-3,87$ & $3,05+/-1,29$ & $3,11+/-0,86$ \\
\hline Group 3 & $8,09+/-6,93$ & $2,91+/-1,50$ & $1,92+/-0,21$ \\
\hline Controls & $5,03+/-1,21$ & $2,56+/-1,03$ & $2,367+/ 0,83$ \\
\hline
\end{tabular}




\section{Discutions}

Increased blood viscosity has been demonstrated in patients with type 2 diabetes, which induce blood hypoperfusion and vascular lesions and eventually lead to diabetic microangiopathy and other circulatory problems. Skovborg et al. showed an increase in blood viscosity even $20 \%$ higher than the control group (10).

Barnes (11) found that low shear viscosity was significantly higher in the 64 long-term diabetic patients compared to the control group

The simplest physical interpretation of the rheological parameters can be as follows: Viscosity is the rate of energy dissipation caused by deformation and alteration of the aggregate of the figurative elements of the blood, especially in terms of erythrocytes, the largest in the blood; elasticity is the evaluation of the erythrocyte property to undergo a kinetic deformation (potential deformation energy).

Viscosity is a determining factor for local flow characteristics. Blood has some behavior; more specifically, there is an exponential reduction in viscosity with increasing shear rate. However, the simple evaluation of viscosity cannot fully characterize the rheological properties of the blood, and it is necessary to corroborate the shear rate which, in turn, will depend on the blood flow and the diameter of the blood vessel. The relative contribution of erythrocytes, the most numerous elements in the blood, is estimated by the value of the hematocrit. Increasing hematocrit will cause an increase in blood viscosity at different shear rates, as is the case with venous circulation (12)

\section{Conclusions}

Blood viscosity could be a major factor who can change the evolution of renal impairment. It is definite the change in the blood viscosity in diabetic persons and implicitelly in those with renal complications. Even if at high shear rates the blood viscosity tends to „draw” a low plateau - close to the one observed in healthy controls, a significant increase of blood viscosity at low share rates was observed in all diabetic groups.

Blood viscosity evaluation may play an important role into detailing the evaluation of diabetic renal impairment.

\section{References}

1. Reenders K, de Nobel E, van den Hoogen HJ ,M Rutten GEHM, van Weel C. D . Diabetes and its long-term complications in general practice: a survey in a well-defined population. Fam Pract 1993;10:169e72.

2. Weir MR. Albuminuria predicting outcome in diabetes: incidence of microalbuminuria in Asia-Pacific Rim. Kidney Int 2004;66:S38e9.

3. Ritz E. Diabetic nephropathy. Saudi J Kidney Dis Transpl. 2006;17:481-490.

4. Mathiesen ER, Ronn B, Storm B, et al. The natural course of microalbuminuria in insulindependent diabetes: a 10-year prospective study. Diabet Med 1995;12:482e7.

5. Lemley KV, Abdullah I, Myers BD, Meyer TW ,Blouch K, Smith WE , Bennett PH, Nelson RG Evolution of incipient nephropathy in type 2 diabetes mellitus. Kidney Int 2000;58:1228e37. Published erratum appears in Kidney Int. 2000;58:2257

6. Warram JH, Gearin G, Laffel L, Krolewski AS Effect of duration of type I diabetes on theprevalence of stages of diabetic nephropathy defined by urinary albumin/ creatinine ratio. J Am Soc Nephrol 1996;7:930e7

7. https://www.usrds.org/reference.aspx US Renal Data System USRDS 2017 Reference Tables N2 (accesat 01.06.2018)

8. Dr.med.Gerhard-W.Schmeisl Deegenberg klinik, Bad Kissingen; Germania Dr. Carmen Săndică.Sursa: JurnaluldeDiabet1/2009

9. Anew Classification ofDiabetic Nephropathy 2014: a report from Joint Committee on Diabetic Nephropathy. Haneda M, Utsunomiya K, Koya D, Babazono T, Moriya T, Makino H, Kimura K, Suzuki Y, Wada T, Ogawa S, Inaba M, Kanno Y, Shigematsu T, Masakane I, Tsuchiya K, Honda K, Ichikawa $\mathrm{K}$, Shide K; Joint Committee on Diabetic Ne phropathy

10. Skovborg, F., A. Nielsen, J.Schlichtkrull, and J. Ditzel, 1966. Blood-viscosity in diabetic patients. Lancet 287:129-131

11. Barnes AJ, Locke P, Scudder PR, 
Dormandy TL, Dormandy JA, Slack J. Is hyperviscosity a treatable component of diabetic microcirculatory disease? Lancet. 1977;2(8042):789-791.)

12. Baskurt OK, Meiselman HJ. Blood rheology and hemodynamics. Semin Thromb Hemost. 2003 Oct;29(5):435-50). 